\title{
Non-drug therapies for lower limb muscle cramps (Review)
}

\author{
Blyton F, Chuter V, Walter KEL, Burns J
}

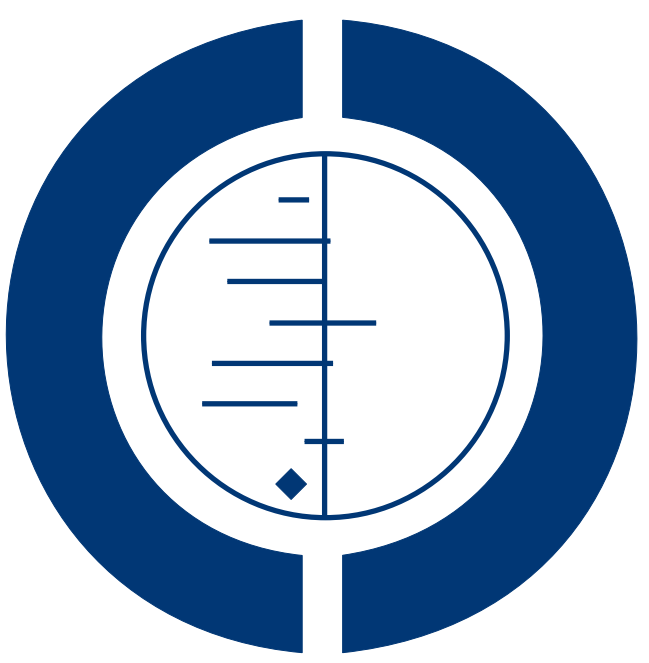

\section{THE COCHRANE COLLABORATION ${ }^{\circledR}$}

This is a reprint of a Cochrane review, prepared and maintained by The Cochrane Collaboration and published in The Cochrane Library 2012, Issue 1

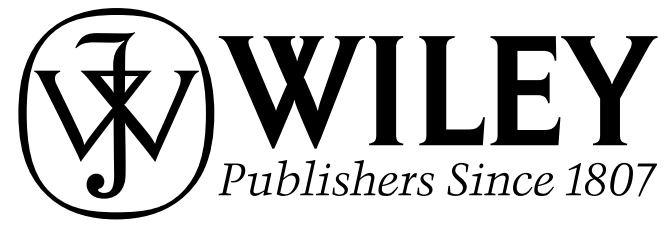

Non-drug therapies for lower limb muscle cramps (Review)

Copyright $\odot 2012$ The Cochrane Collaboration. Published by John Wiley \& Sons, Ltd. 
TABLE OF CONTENTS

HEADER . . . . . . . . . . . . . . . . . . . . . . . . . . . . . . . . . . . . 1

ABSTRACT . . . . . . . . . . . . . . . . . . . . . . . . . . . . . . . . . . . . . . . . . . . . . . .

PLAIN LANGUAGE SUMMARY . . . . . . . . . . . . . . . . . . . . . . . . . . . . . . . . . . . .

SUMMARY OF FINDINGS FOR THE MAIN COMPARISON $\quad$. . . . . . . . . . . . . . . . . . . . . . . . . .

BACKGROUND . . . . . . . . . . . . . . . . . . . . . . . . . . . . . . . . . . . . 5

OBJECTIVES . . . . . . . . . . . . . . . . . . . . . . . . . . . . . . . . . . . . . . . . . . . .

METHODS . . . . . . . . . . . . . . . . . . . . . . . . . . . . . . . . . . . . . .

RESULTS . . . . . . . . . . . . . . . . . . . . . . . . . . . . . . . . . . . . . . . 8

Figure 1. . . . . . . . . . . . . . . . . . . . . . . . . . . . . . . . . . . . . .

DISCUSSION . . . . . . . . . . . . . . . . . . . . . . . . . . . . . . . . . . . . . . . . . . . . . .

AUTHORS' CONCLUSIONS . . . . . . . . . . . . . . . . . . . . . . . . . . . . . . . . . . . 12

ACKNOWLEDGEMENTS . . . . . . . . . . . . . . . . . . . . . . . . . . . . . . . . . . . 13

REFERENCES . . . . . . . . . . . . . . . . . . . . . . . . . . . . . . . . . . . . . . 13

CHARACTERISTICS OF STUDIES . . . . . . . . . . . . . . . . . . . . . . . . . . . . . . . . . . . . . .

DATA AND ANALYSES . . . . . . . . . . . . . . . . . . . . . . . . . . . . . . . . . . . . . . . . . . . .

HISTORY . . . . . . . . . . . . . . . . . . . . . . . . . . . . . . . . . . . . . . 21

CONTRIBUTIONS OF AUTHORS . . . . . . . . . . . . . . . . . . . . . . . . . . . . . . . . . . . . . . . . . . . .

DECLARATIONS OF INTEREST . . . . . . . . . . . . . . . . . . . . . . . . . . . . . . . 21

SOURCES OF SUPPORT . . . . . . . . . . . . . . . . . . . . . . . . . . . . . . . . . . . . . . . . . . . . . . .

DIFFERENCES BETWEEN PROTOCOL AND REVIEW . . . . . . . . . . . . . . . . . . . . . . . . . . . 22

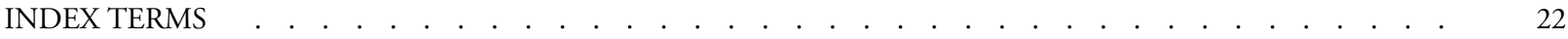

Non-drug therapies for lower limb muscle cramps (Review)

Copyright $\odot 2012$ The Cochrane Collaboration. Published by John Wiley \& Sons, Ltd. 


\title{
[Intervention Review]
}

\section{Non-drug therapies for lower limb muscle cramps}

\author{
Fiona Blyton $^{1,2}$, Vivienne Chuter ${ }^{1}$, Kate EL Walter ${ }^{1}$, Joshua Burns ${ }^{3}$ \\ ${ }^{1}$ School of Health Sciences, Faculty of Health, The University of Newcastle, Ourimbah, Australia. ${ }^{2}$ Discipline of Paediatrics \& Child \\ Health, University of Sydney, Westmead, Australia. ${ }^{3}$ Faculty of Health Sciences, The University of Sydney, and Institute for Neuroscience \\ and Muscle Research, The Children's Hospital at Westmead, Westmead, Australia
}

Contact address: Fiona Blyton, fiona.blyton@newcastle.edu.au.

Editorial group: Cochrane Neuromuscular Disease Group.

Publication status and date: New, published in Issue 1, 2012.

Review content assessed as up-to-date: 13 September 2011.

Citation: Blyton F, Chuter V, Walter KEL, Burns J. Non-drug therapies for lower limb muscle cramps. Cochrane Database of Systematic Reviews 2012, Issue 1. Art. No.: CD008496. DOI: 10.1002/14651858.CD008496.pub2.

Copyright (C) 2012 The Cochrane Collaboration. Published by John Wiley \& Sons, Ltd.

\begin{abstract}
A B S T R A C T
Background

About one in every three adults are affected by lower limb muscle cramps. For some people, these cramps reduce quality of life, quality of sleep and participation in activities of daily living. Many interventions are available for lower limb cramps, but some are controversial, no treatment guidelines exist, and often people experience no benefit from the interventions prescribed.
\end{abstract}

\section{Objectives}

To assess the effects of non-drug, non-invasive treatments for lower limb cramp.

\section{Search methods}

We searched the Cochrane Neuromuscular Disease Group Specialized Register (13 September 2011) using the terms: cramp, spasm, contracture, charley horse and lower limb, lower extremity, foot, calf, leg, thigh, gastrocnemius, hamstring, quadriceps. We also searched CENTRAL (2011, Issue 3), MEDLINE (January 1966 to August 2011) and EMBASE (January 1980 to August 2011) and the reference lists of included studies. There were no language or publication restrictions.

\section{Selection criteria}

All randomised controlled trials of non-drug, non-invasive interventions trialled over at least four weeks for the prevention of lower limb muscle cramps in any group of people. We excluded, for example, surgery, acupuncture and dry-needling, as invasive interventions. We selected only trials that included at least one of the following outcomes: cramp frequency, cramp severity, health-related quality of life, quality of sleep, participation in activities of daily living and adverse outcomes.

\section{Data collection and analysis}

Two authors independently selected trials, assessed risk of bias and cross checked data extraction and analysis. A third author was to arbitrate in the event of disagreement. We asked the authors of five trials for information to assist with screening studies for eligibility and received four responses.

Non-drug therapies for lower limb muscle cramps (Review)

Copyright @ 2012 The Cochrane Collaboration. Published by John Wiley \& Sons, Ltd. 


\section{Main results}

One trial was eligible for inclusion. All participants were age 60 years or over and had received a repeat prescription from their general practitioner of quinine for nighttime cramps in the preceding three months. This review includes data from only those participants who were advised to continue taking quinine. Forty-nine participants were advised to complete lean-to-wall calf muscle stretching held for $10 \mathrm{~s}$ three times per day. Forty-eight participants were allocated to a placebo stretching group. After 12 weeks, there was no statistically significant difference in recalled cramp frequency between groups. No "significant" adverse effect was reported. Limitations in the study's design impede interpretation of the results and clinical applicability.

\section{Authors' conclusions}

There is limited evidence on which to base clinical decisions regarding the use of non-drug therapies for the treatment of lower limb muscle cramp. Serious methodological limitations in the existing evidence hinder clinical application. There is an urgent need to carefully evaluate many of the commonly recommended and emerging non-drug therapies in well designed randomised controlled trials.

\section{PLAIN LANGUAGE SUMMARY}

\section{Non-drug therapies for lower limb muscle cramps}

Lower limb muscle cramps are a common problem that can affect any person, but cramps mostly occur during exercise, at nighttime in older people, in pregnant women, in people with a neurological disease and during kidney dialysis. Non-drug treatments are described as being effective for the treatment of muscle cramps. Non-drug treatments include muscle stretching, physical exercise, avoidance of physical fatigue, massage, relaxation, heat therapy, weight loss, sensory nerve stimulation, ankle splints worn while sleeping, and changes to sleeping and sitting positions. We did not include invasive interventions such as surgery, acupuncture or dry-needling in this review.

Only one randomised trial has assessed the effectiveness of a non-drug treatment for lower limb muscle cramp. This trial evaluated daytime calf muscle stretching to prevent nighttime muscle cramp in adults age 60 years and over who had received a repeat prescription of quinine for nighttime cramps in the preceding three months. Forty-nine participants were advised to complete lean-to-wall calf muscle stretching held for $10 \mathrm{~s}$ three times per day. Forty-eight participants were allocated to a placebo stretching group. After 12 weeks, there was no statistically significant difference in the frequency of cramps, as recalled by the participants, between groups. No "significant" adverse effect was reported. Owing to serious limitations in the design of the trial, it is impossible to determine from the available evidence whether or not calf muscle stretching can prevent recurrent lower limb muscle cramp.

Further research is required to determine the effectiveness of non-drug treatments for lower limb muscle cramp.

Non-drug therapies for lower limb muscle cramps (Review) 


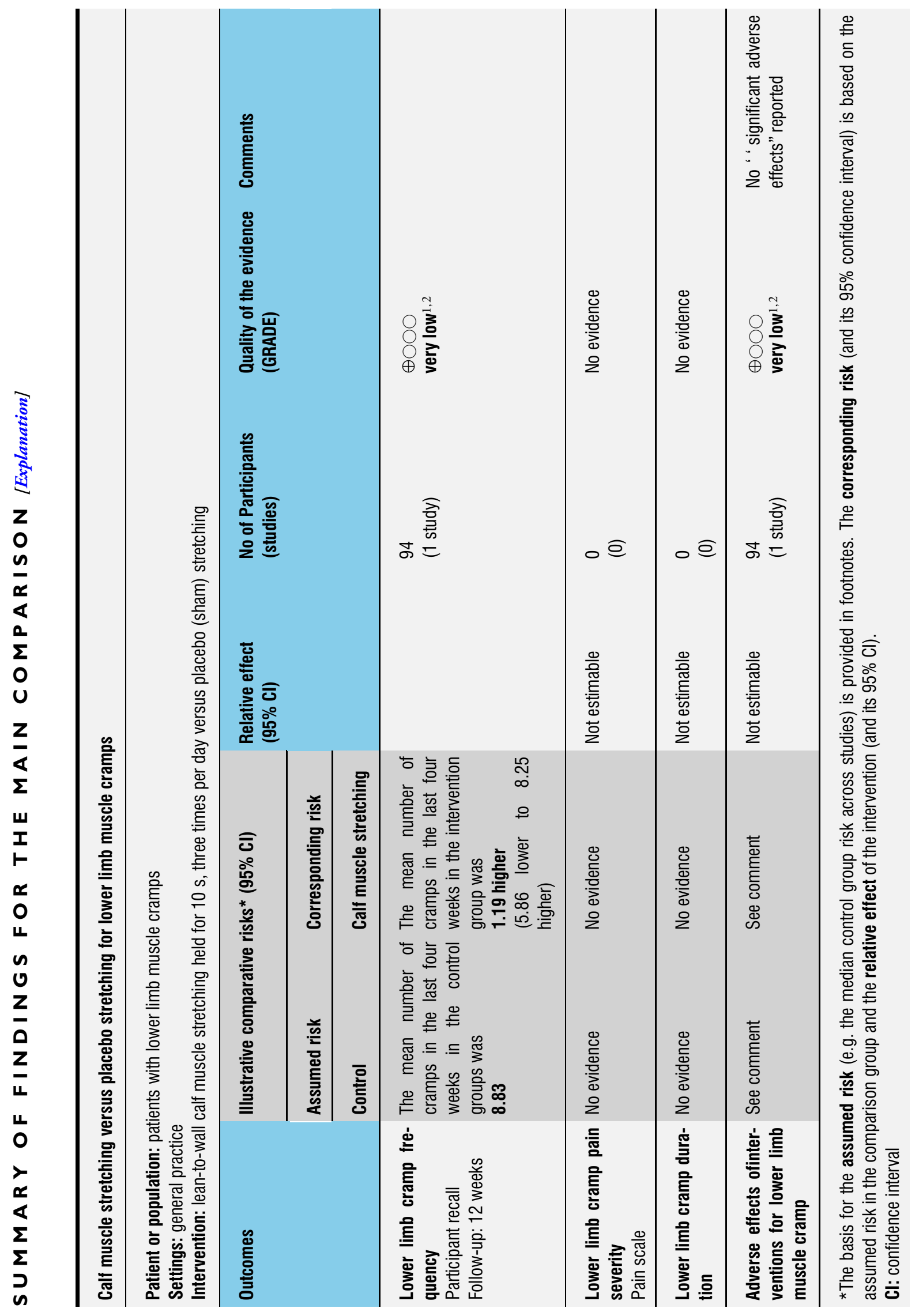

Non-drug therapies for lower limb muscle cramps (Review)

Copyright @ 2012 The Cochrane Collaboration. Published by John Wiley \& Sons, Ltd. 


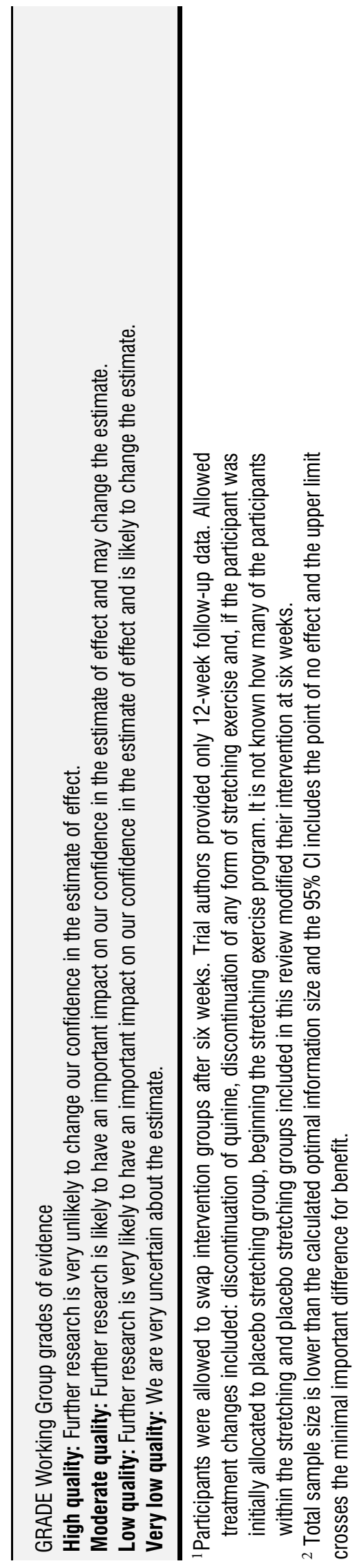

Non-drug therapies for lower limb muscle cramps (Review)

Copyright @ 2012 The Cochrane Collaboration. Published by John Wiley \& Sons, Ltd. 


\section{B A C K G R O U N D}

\section{Description of the condition}

Muscle cramps are sudden, involuntary, painful contractions of skeletal muscle (Norris 1957; Jansen 1991a; El-Tawil 2010) that are characterised electrically by repetitive firing of motor unit action potentials at high rates up to 150 per s (Miller 2005). Cramps can be excruciatingly painful (Kanaan 2001; Jansen 2002) and can cause delayed onset muscle soreness (a type of painful muscle damage that typically produces pain for 2 to 14 days) (Leung 1999; Jansen 2002). Muscle cramps can also interfere with sleep (Gootnick 1943; Gentili 1997; Gulich 1998) and activities of daily living (Matsumoto 2009); cause distress (Naylor 1994; Butler 2002); reduce quality of life (Kanaan 2001; Miller 2005; Shaker 2005; Kobrin 2007); limit sports participation and performance; and lead to chronic underdialysis in people undergoing haemodialysis (Canzanello 1992; Kobrin 2007). In one of the earliest case series reports, Gootnick 1943 reported three people whose sleep was so troubled by cramps during the night that they had been unable to sleep for months except in an armchair.

Muscle cramp can occur at any time throughout the day or night (Abdulla 1999) and can affect people of any age (Jansen 1991; Miller 2005), although they are uncommon in children less than eight years of age (Leung 1999). Cramps usually affect muscles of the legs (Naylor 1994; Hirai 2000), particularly the calf muscles (Jansen 1991; Manjra 1996; Abdulla 1999; Leung 1999). Most cramps resolve spontaneously within 10 minutes (Naylor 1994; Abdulla 1999) but are reported to last up to one hour (Abdulla 1999). In most cases, cramps occur irregularly, often appearing and disappearing spontaneously for long periods, irrespective of treatment (Jansen 1999).

No large, randomly sampled population studies have been conducted to determine the prevalence of lower limb muscle cramps. In a nationwide, randomised study of general muscle cramps in nearly 2000 Dutch adults, approximately one in every three people reported at least one muscle cramp during the prior year (Jansen 1991a). Similarly, of over 1000 people surveyed in southern Germany, approximately one in every three people reported a history of nocturnal calf cramp and one in every four had experienced cramp within the four weeks prior to completing the questionnaire (Gulich 1998). In a separate study of 365 people aged 65 years and over, one in two people reported leg cramps at rest (for example while sleeping) (Abdulla 1999).

Compared to the general population, leg cramps are more prevalent in pregnant women (Jansen 1991; Jansen 1991a); people over 60 years of age (Naylor 1994; Gulich 1998; Hirai 2000); people undergoing haemodialysis (Canzanello 1992; Kobrin 2007); people with cirrhosis (Angeli 1996), fibromyalgia (Yunus 1996), arthritis (Yunus 1996; Abdulla 1999), lower motor neuron disease (for example amyotrophic lateral sclerosis) (Forshew 2003), lumbar spinal canal stenosis (Matsumoto 2009), peripheral neurological deficit (Haskell 1997), paraesthesia (Yunus 1996) or vari- cose veins (Gulich 1998; Hirai 2000); and children and adults with Charcot-Marie-Tooth disease (Burns 2009; Redmond 2009). There is no consistent relationship between cramp prevalence and gender (Jansen 1991; Naylor 1994; Manjra 1996; Gulich 1998; Abdulla 1999; Hirai 2000), serum electrolyte levels (Oboler 1991; Haskell 1997; Sulzer 2005), dehydration (Manjra 1996; Sulzer 2005; Schwellnus 2007), heart disease (Oboler 1991; Haskell 1997; Gulich 1998; Abdulla 1999) or diabetes mellitus (Oboler 1991; Gulich 1998).

\section{Description of the intervention}

Many interventions are available for lower limb muscle cramps. The most common interventions can be broadly categorised as drug or non-drug. Common drug interventions include quinine sulphate (El-Tawil 2010), gabapentin (Miller 2005), magnesium (Frusso 1999; Roffe 2002; Sohrabvand 2006), vitamin E (Connolly 1992; Burnakis 2000), calcium channel blockers (Baltodano 1988), naftidrofuryl oxalate (Young 1993) and calcium (Sohrabvand 2006). Non-drug interventions reported in the literature include: muscle stretching (Daniell 1979; Jones 1983; Simchak 1991; Leclerc 1996; Leung 1999; Kanaan 2001; Miller 2005; Matsumoto 2009); massage (Jones 1983; Kanaan 2001; Matsumoto 2009); relaxation (Joekes 1982); sensory nerve stimulation (Bentley 1996); footwear changes (Roberts 1965); weight loss (Roberts 1965); physical exercise (Miller 2005); avoiding physical fatigue (Roberts 1965); heat therapy (Jones 1983); compression garments (Young 2009); night ankle dorsiflexion splints (Miller 2005); placebo (Miller 2005); reassurance (Butler 2002); and changes to sleeping (Gootnick 1943; Moss 1948; Cutler 1984; Warburton 1987; Abdulla 1999; Leung 1999; Kanaan 2001) and sitting (Roberts 1965) position. More controversial historical interventions include sleeping with a horseshoe (Simchak 1991), a magnet (Fowler 1973), corks (Warburton 1987) or potatoes (Warburton 1987) beneath the mattress.

\section{Why it is important to do this review}

Management of leg cramps can be frustrating (Riley 1995) and difficult (Butler 2002) for physicians and patients alike. Many people experience no benefit from the interventions prescribed (Sontag 1988; Abdulla 1999; Miller 2005) and many more receive no intervention at all (Naylor 1994; Gulich 1998; Abdulla 1999). Only two Cochrane systematic reviews have focused on interventions for muscle cramps. These reviews assessed the treatment of muscle cramps in pregnancy (Young 2002) and the effectiveness of quinine for muscle cramps (El-Tawil 2010). Two other reviews, currently in protocol stage, will evaluate intervention for muscle cramp in amyotrophic lateral sclerosis (Weber 2003) and magnesium for skeletal muscle cramps (Garrison 2011). The Cochrane systematic review of quinine for muscle cramps (El-Tawil 2010) 
concluded that, despite moderate quality evidence that quinine significantly reduces cramp frequency, intensity and cramp days more than placebo, alternative interventions for muscle cramp should be investigated due to the risk of adverse effects.

A systematic review of non-drug interventions for lower limb muscle cramps will serve two purposes. Firstly, it will enable healthcare providers, users, and policy decision makers to make better informed decisions about the treatment of lower limb muscle cramps. Secondly, it will identify for researchers interventions that require further evaluation in clinical trials.

\section{O B JECT IVES}

To evaluate the effectiveness of non-drug interventions for lower limb muscle cramps.

\section{METHODS}

\section{Criteria for considering studies for this review}

\section{Types of studies}

All randomised controlled trials (RCTs) of non-drug interventions for the prevention of lower limb muscle cramps. We excluded trials of acute treatment of muscle cramps. We accepted any diagnosis of cramp unless there was clear contradiction with the broad definition used in this review (cramp as a sudden, involuntary, painful contraction of skeletal muscle). We planned to report definitions of 'cramp' used in included studies in the table Characteristics of included studies. We contacted authors for clarification if: (1) 'cramp' was diagnosed but not defined, (2) authors diagnosed commonly used synonyms for cramp (for example, spasm) or (3) authors described the problem in such a way that we suspected muscle cramp (for example, if they described the problem as a sudden, painful contraction of skeletal muscle).

\section{Types of participants}

We included all people (including men, women and children) who experience lower limb muscle cramp. We included cramp during any activity or condition, including (but not limited to) cramp associated with exercise, pregnancy, haemodialysis, sleep and neurological conditions.

\section{Types of interventions}

We included all non-drug and non-invasive interventions used for at least four weeks. These may have included, but were not limited to, muscle stretching, splints, massage, warmth, change in sleeping position, placebo, relaxation, footwear, weight loss, compression garments, transcutaneous nerve stimulation, muscle strengthening, regular exercise, and changes to physical activity.

We excluded all drug interventions and invasive interventions (including surgery and acupuncture/dry needling). For this review, drug interventions included any intervention taken orally (such as tablets, capsules, tonics), by injection, by rectal or vaginal suppository or by inhalation. We also excluded topically applied medicines (for example glyceryl trinitrate patches); however, topically applied preparations that are not thought to alter body function directly and independently (such as oils used in massage) were eligible for inclusion.

We also excluded reflexology.

We only included trials that included drug or invasive interventions if at least two other groups did not receive a drug or invasive intervention.

\section{Types of outcome measures}

\section{Primary outcomes}

- Cramp frequency, measured as number of cramps per week

When analysing cramp frequency, we planned to use change from baseline frequency where possible. If change scores with measures of variability were not available for all trials included in the same analysis, we planned to combine change scores and follow-up values using standardised mean differences (SMD).

\section{Secondary outcomes}

- Adverse outcomes

- Cramp severity, including pain severity (measured using any validated pain assessment tool, for example, a visual analogue scale) and duration of cramp (measured in seconds)

- Health-related quality of life (measured by any validated assessment tool, for example, SF-36 survey)

- Quality of sleep (measured by any validated assessment tool, for example, MOSleep survey)

- Participation in activities of daily living, including physical activity (measured by any validated assessment tool)

If data from only one study were included in an analysis, we measured the outcome at the time point used in the original study. If data from more than one trial were included in an analysis, we planned to group the outcomes in the time points 'four weeks to three months' and 'more than three months'. In this instance, the time point 'more than three months' was planned to be the primary outcome and the time point 'four weeks to three months' 
was planned to be a secondary outcome. We planned to standardise all outcome data combined in meta-analysis to an appropriate follow-up period, for example, cramps per week after four months combined with cramps per week after six months.

'Summary of findings' tables were prepared for the outcomes cramp frequency, cramp pain severity, cramp duration and adverse effects.

\section{Search methods for identification of studies}

\section{Electronic searches}

We searched the Cochrane Neuromuscular Disease Group Specialized Register (13 September 2011) using the terms 'cramp', 'spasm', 'contracture', 'charley horse' and 'lower limb', 'lower extremity', 'foot', 'calf', 'leg', 'thigh', 'gastrocnemius', 'hamstring' or 'quadriceps'. We also searched CENTRAL (2011, Issue 3), MEDLINE (January 1966 to August 2011) and EMBASE (January 1980 to August 2011). The detailed search strategies are in the appendices: Appendix 1 (MEDLINE), Appendix 2 (EMBASE) and Appendix 3 (CENTRAL). There were no language or publication restrictions.

\section{Searching other resources}

We checked the references of the included study for other suitable trials. The first author of the included study was contacted via email to assist in identifying relevant unpublished and published trials.

\section{Data collection and analysis}

\section{Selection of studies}

Two authors (FB and KW) independently assessed the titles and abstracts of all trials identified by the search. The same two authors then independently assessed for inclusion full-text copies of potentially relevant studies. Authorship and results were not masked. We resolved disagreements by discussion between review authors or, when necessary, arbitration by a third review author (JB). We planned to contact study authors if arbitration by the third reviewer did not resolve the dispute. If this was unsuccessful, we were to report the disagreement in the review. This was not required. We sought guidance from the Cochrane Neuromuscular Group regarding the eligibility of one trial (Coppin 2005) for inclusion. Guidance was provided and followed.

\section{Data extraction and management}

One review author (FB) extracted data from the published report using a standardised, pilot tested form and a second review author (KW) performed cross checks. We contacted the study authors as necessary to provide missing information or clarifications. We planned to resolve disagreements by discussion between review authors or, if necessary, arbitration by a third review author (JB). This was not required.

\section{Assessment of risk of bias in included studies}

Two review authors (FB and KW) independently rated risk of bias of the included trial using the following criteria as described in the Cochrane Handbook of Systematic Reviews of Interventions (Higgins 2011):

- sequence generation;

- concealment of allocation;

- blinding;

- incomplete data;

- selective outcome reporting;

- other sources of bias, such as financial conflicts of interest and single author or single centre trials.

Each criterion was assigned a judgement of 'high risk', 'low risk' or 'unclear risk' relating to the risk of bias for that entry. 'Unclear risk' indicates an unclear or unknown risk of bias; or if an entry is not relevant to the study at hand. Results are presented in the 'Risk of bias' table. A 'Risk of bias summary' figure was generated using Review Manager 5 to present all of the judgements in a crosstabulation of study by entry.

If we were required to contact study authors for missing information regarding risk of bias, we planned to ask open-ended questions to reduce the risk of leading, for example the open-ended question 'How did you decide which treatment the next patient should receive?' was to be used in preference to 'Did you conceal the allocation sequence?'. This was not required.

\section{Measures of treatment effect}

Where possible, we analysed continuous data using mean differences (MD) and 95\% confidence intervals (CI). If meta-analysis was required to pool data derived from different measurement scales, we planned to perform standardised mean difference (SMD) analyses. This was not required. We analysed count data (for example number of muscle cramps) as continuous data (mean number of cramps per person per week).

We planned to report results for dichotomous data as risk ratios (RR) with 95\% CI.

\section{Unit of analysis issues}

We planned to include cross-over trials; however, only data from the first phase of intervention were to be considered, as clinical trials of interventions for muscle cramp have detected significant 
carryover effects (particularly for quinine) (Dunn 1993; Jansen 1997; Coppin 2005) and the effectiveness of washout periods for interventions for muscle cramps is unknown. Due to the substantial and variable carryover effect of quinine, we excluded studies that discontinued quinine less than three months prior to intervention within the trial.

\section{Dealing with missing data}

Where available, we planned to extract data from intention-totreat analyses. If the original researchers did not perform intentionto-treat analyses and sufficient raw data were available, we planned to complete intention-to-treat analyses before entering data into the Cochrane statistical package Review Manager (RevMan) 5.1.2 (RevMan 2011), to limit attrition bias.

\section{Assessment of heterogeneity}

We planned to assess clinical heterogeneity across trials and if trials were sufficiently clinically homogenous in terms of participants, interventions, and outcomes we would have included them in meta-analysis.

We planned to quantify inter-trial statistical inconsistency using I

2 (Higgins 2011).

The $\mathrm{I}^{2}$ value was to be calculated by:

$\mathrm{I}^{2}=100 \%[(\mathrm{Q}-\mathrm{df}) / \mathrm{Q}]$

where $\mathrm{Q}$ is Cochran's heterogeneity, $\mathrm{Chi}^{2}$ statistic and $\mathrm{df}$ is the degrees of freedom. The Cochran's $Q$ is determined by summing the squared deviations (SDs) of each trial's estimate from the overall meta-analytic estimate and a $\mathrm{P}$ value obtained by comparing the statistic with $\mathrm{a} \mathrm{x}^{2}$ distribution with $\mathrm{k}-1$ degrees of freedom (where $\mathrm{k}$ is the number of trials). We planned to use the following guide to interpret the $\mathrm{I}^{2}$ values:

- 0 to $40 \%$ might not be important;

- 30 to $60 \%$ may represent moderate heterogeneity;

- 50 to $90 \%$ may represent substantial heterogeneity;

- 75 to $100 \%$ considerable heterogeneity.

If heterogeneity could not readily be explained, we planned to use a random-effects model to incorporate heterogeneous trials in meta-analysis.

\section{Data synthesis}

We used RevMan for statistical analyses. One author (FB) entered statistical data into RevMan and a second author (KW) checked the data.

\section{Subgroup analysis and investigation of heterogeneity}

Providing sufficient data were available, we planned to perform subgroup analysis according to cramp type/aetiology, for example, rest cramp versus exercise-associated cramp versus haemodialysis cramp versus cramp in people with neuromuscular disease.
Meta-analyses of subgroups were to follow the same methodological principles as the primary analysis. If meta-analyses were performed within multiple subgroups, we planned to compare the magnitude of effect estimates for subgroups informally between groups. We were to have considered non-overlap of summary estimate CIs to indicate statistical significance. If CIs overlapped to a small degree, we would have considered the possibility of a statistically significant difference (Higgins 2011).

We did not plan to compare the statistical significance of the pooled effect estimates for individual subgroups as the likely unequal information loading subgroups would have affected the power to detect effects (Higgins 2011).

\section{Sensitivity analysis}

We planned to perform sensitivity analyses by including only studies of high methodological quality (low to moderate risk of bias). If we had found all trials to have a high risk of bias, we planned to perform sensitivity analyses by excluding trials not concealing allocation or blinding the participants.

If one or more outliers were found to contribute to heterogeneity, and a reason for the outlying result was apparent, we planned to perform analyses both with and without outlying trials as a component of sensitivity analysis (Higgins 2011).

\section{R E S U L T S}

\section{Description of studies}

See: Characteristics of included studies; Characteristics of excluded studies.

\section{Results of the search}

Electronic searches retrieved a total of 1351 citations (247 from CENTRAL; 717 from EMBASE; 356 from MEDLINE; and 31 from the Cochrane Neuromuscular Disease Group Specialized Register). Of these, we identified 19 as potentially relevant. We obtained translation of published reports from French, Swedish, Chinese and German as necessary, to determine eligibility. Searching of reference list of the included trial did not retrieve any additional potentially relevant trials. We contacted authors of five trials to provide additional information to assist with screening: four replied (Vayssairat 2000; Coppin 2005; Warke 2006; Schyns 2009); one did not (Carpenter 1995).

\section{Included studies}

One trial with a total of 191 participants was eligible for inclusion (Coppin 2005). Details of this trial are presented in the table 
Characteristics of included studies. This trial was identified by electronic searching.

All participants were age 60 years or over and had received a repeat prescription from their general practitioner of quinine for nighttime cramps in the preceding three months. Participants were allocated to one of four groups: (1) advised to discontinue taking quinine and begin a calf stretching program; (2) advised to discontinue taking quinine and begin a placebo stretching program; (3) advised to continue taking quinine and begin a calf stretching program; and (4) advised to continue taking quinine and begin a placebo stretching program.

No washout period was provided for those participants advised to discontinue taking quinine, which excludes two groups from this review. This review includes only the 97 participants who were advised to continue taking quinine. Of these participants, $49(51 \%)$ were male, the mean age was 74.3 years (standard error of the mean (SEM 0.6)) and at baseline the recalled number of cramps in the previous four weeks was 10.4 (SEM 1.76).

Each participant was allocated to either a calf stretching or placebo stretching group. Calf stretches were performed by leaning into a wall for $10 \mathrm{~s}$ three times per day. The stretches and placebo stretches are described in detail in the table Characteristics of included studies. After six weeks, participants were told that they could continue the stretching exercises if they wished and also decide themselves whether or not to continue taking quinine tablets. Participants in the placebo stretching group were also given an instruction sheet describing the stretching exercise program. Published results in Coppin 2005 are only for 1, 2 and 12 week followup and there is no separation within the stretching and placebo stretching groups of those participants who continued quinine versus those who discontinued quinine.

In an attempt to avoid the confounding effects of changing interventions and to exclude participants who were advised to discontinue taking quinine, trial authors were contacted to provide six-week follow-up data for the participants who were advised to continue taking quinine in the stretching and placebo stretching groups. Only 12 weeks follow-up data were provided for the primary outcome 'number of cramps in the last four weeks'.

\section{Excluded studies}

We excluded 18 of the potentially relevant trials upon reading the full-text versions. Reasons for exclusion were: 14 did not isolate lower limb muscle cramp as an outcome measure (Carpenter 1995; Cramp 1995; Vayssairat 2000; Thaler 2001; Lawani 2003; Laessøe 2004; Warke 2006; Wei 2006; Xue 2006; Goodwin 2007; Miller 2007; Ippolito 2008; Liu 2009; Schyns 2009); four provided the intervention for less than four weeks (Laessøe 2004; Goodwin 2007; Miller 2007; Ippolito 2008); three assessed only drug therapy (Stern 1966; Mauss 1970; Liu 2009); two were not randomised or controlled clinical trials (as defined by Higgins 2011); one did not isolate data from participants who reported lower limb muscle cramp (Nilsson 2008); and one used a non-validated scale to measure health-related quality of life (Nilsson 2008). Details of individual trials are presented in the table Characteristics of excluded studies.

\section{Risk of bias in included studies}

Assessment of risk of bias for Coppin 2005 is described in the table Characteristics of included studies and is summarised in Figure 1.

Non-drug therapies for lower limb muscle cramps (Review) 
Figure I. Risk of bias summary: review authors' judgements about each risk of bias item for each included study.

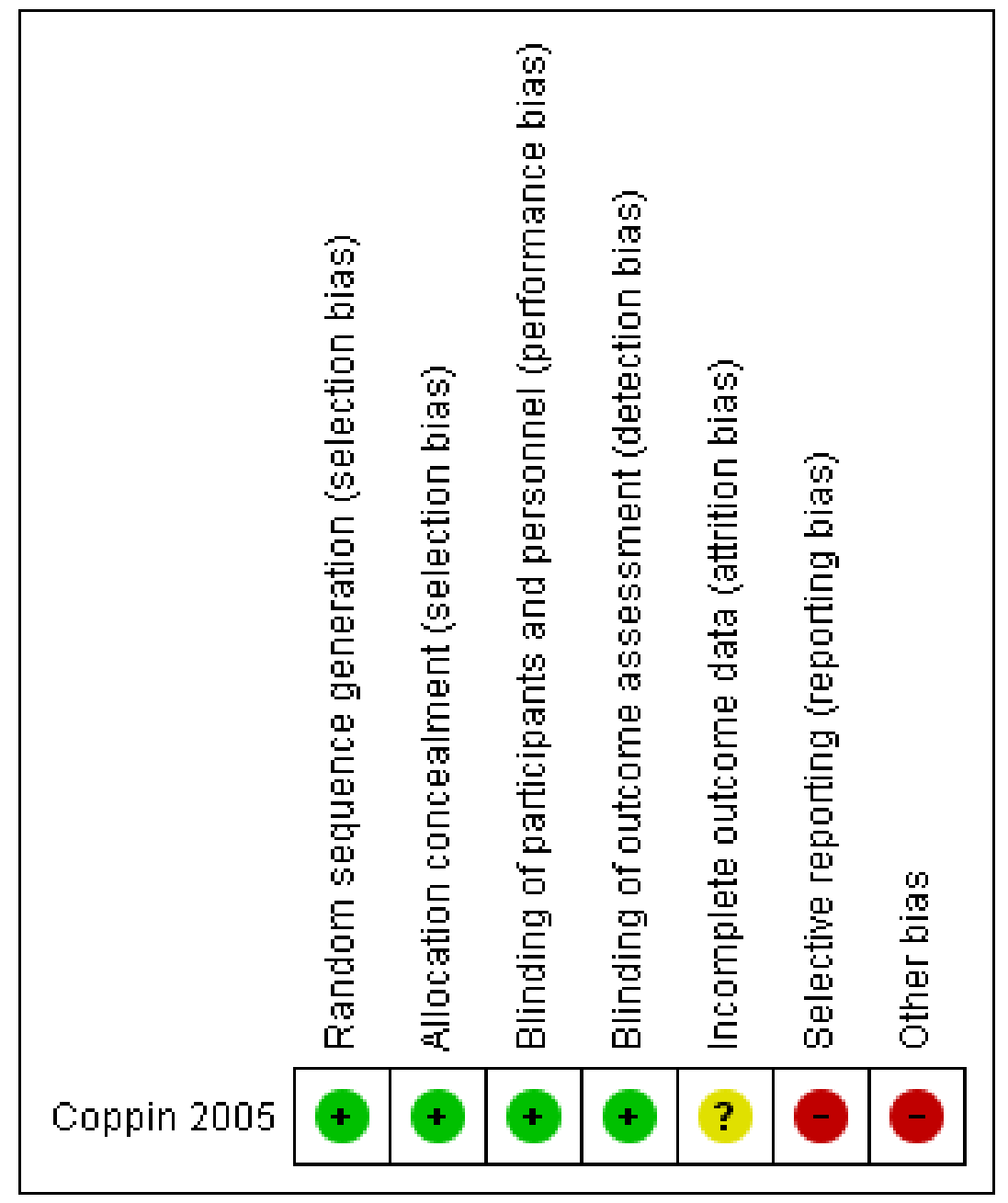

\section{Allocation}

Allocation order was concealed using sealed, numbered, opaque envelopes containing intervention instructions.

\section{Blinding}

Participants were blinded to their group allocation by comparing calf muscle stretching to "placebo exercise", which "was devised to be of comparable duration and simplicity to the intervention stretching exercise, but was passive and involved negligible stretching of the muscles of the calf and foot". Researchers "sought to minimise intervention contamination by terming the stretching and placebo exercises as 'standing' and 'lying' exercises, respec- tively”. Outcome assessors were blinded by using self-report postal questionnaires.

\section{Incomplete outcome data}

In the 12-week data provided by the authors, data is missing for one participant from the intervention group and two participants from the control group. Reasons for missing data are not provided.

\section{Selective reporting}

The online protocol (ISRCTN26051665) states that outcomes would include duration of leg cramps and subsequent GP atten- 
dance. Data for these outcomes are not provided in the published paper.

\section{Other potential sources of bias}

After 12 weeks, participants were asked to recall how many night cramps they had experienced in the preceding 4 weeks. Participants might be subject to recall bias.

As discussed under Included studies, participants were allowed to swap intervention groups after six weeks. When contacted, trial authors provided only 12-week follow-up data and did not respond to further request for six-week follow-up data. Permitted treatment changes after six weeks included discontinuation of quinine, discontinuation of any form of stretching exercise and, if the participant was initially allocated to the placebo stretching group, beginning the stretching exercise program. The study does not report how many of the participants within the stretching and placebo stretching groups included in this review modified their intervention at six weeks. This seriously limits the interpretability and clinical applicability of results.

\section{Effects of interventions}

See: Summary of findings for the main comparison Calf muscle stretching versus placebo stretching for lower limb muscle cramps In Coppin 2005, of those participants advised to continue taking quinine, 49 were allocated to the stretching group and 48 were allocated to the placebo stretching group. No participant was lost to follow-up, yet owing to incomplete data, we included only 48 participants from the stretching group and 46 participants from the placebo stretching group in the analysis. As change-from-baseline frequencies and SD were not available for data analysis, plain follow up scores and SD were used.

After 12 weeks, participants were asked to recall how many cramps they had experienced in the previous four weeks. The difference in mean number of recalled cramps between the stretching group (mean 10.02, SD 17.67) and the placebo stretching group (mean 8.83, SD 17.23) was not statistically significant (MD 1.19, 95\% CI -5.86 to 8.25 , Analysis 1.1). There were no "significant adverse effects" reported. No definition of "significant adverse effects" was provided.

\section{DISCUSSION}

This review included only one study. The included study aimed to assess the effect of (1) calf stretching exercises and (2) cessation of quinine on nighttime muscle cramp. Only the effect of calf stretching exercises was considered in this review. This study compared 49 people randomly allocated to a lean-to-wall calf stretching group with 48 people randomly allocated to a placebo (fake) stretching group. Both groups performed their stretches for $10 \mathrm{~s}$ three times per day. All participants were also taking quinine for their muscle cramps. After six weeks, participants could decide for themselves whether or not to continue with their allocated stretches and quinine tablets. Outcome data were provided by the authors, but only for 12-week follow-up. At the 12-week followup, participants were asked how many cramps they had experienced in the last four weeks.

\section{Summary of main results}

There is very low quality evidence that lean-to-wall calf muscle stretching held for $10 \mathrm{~s}$ three times per day does not reduce frequency of nighttime cramp (of unspecified muscles) after 12 weeks in people aged 60 years and over who have also been prescribed quinine for muscle cramping. See Summary of findings for the main comparison.

\section{Overall completeness and applicability of evidence}

The evidence for the use of non-drug therapies for lower limb muscle cramps is overwhelmingly incomplete. Of all types of lower limb muscle cramp (for example, cramp associated with exercise, pregnancy, haemodialysis, sleep and neurological conditions) and of all available non-drug therapies (for example, muscle stretching, massage, weight loss, physical exercise, avoiding physical fatigue, heat therapy, compression garments, night ankle dorsiflexion splints, sensory nerve stimulation, footwear changes, and changes to sleeping and sitting position), only one small study has investigated calf muscle stretching for nighttime cramp in people aged 60 years and over who had been given a repeat prescription of quinine for night cramps in the previous three months.

The applicability of the available evidence is severely limited by deficiencies in study design. These limitations are discussed in more detail below.

\section{Quality of the evidence}

The quality of the evidence included in this review is very low Figure 1. Some strengths of the trial include: (1) the allocation order was concealed (that is, researchers and participants did not know to which group they would be allocated before agreeing to participate) and (2) participants were blinded to their group allocation (that is, participants were not aware if they were in the true stretching or fake stretching group). Some weaknesses of the trial include: (1) there is unexplained missing data for one participant in the true stretching group and two participants in the fake stretching group and (2) outcomes reported in the published paper are different to those listed in the registered online protocol (research plan). Other weaknesses and limitations of the study are discussed below. 


\section{Limitations of the study design}

After six weeks, participants in both the stretching and placebo stretching groups were allowed to swap or discontinue stretching treatments and to decide for themselves whether or not to continue taking quinine. As we included only those participants who were advised at baseline to continue taking quinine, no published data were suitable for use in analysis and trial authors provided only 12 -week follow-up data when contacted. It is not known how many participants in the stretching and placebo stretching groups included in this review swapped or discontinued stretching exercises, or discontinued taking quinine after six weeks. This study design does not reflect clinical practice and seriously limits interpretation as it is impossible to isolate the effect of the intervention assigned at baseline.

The portion of the published study included in this review is underpowered to detect a clinically important difference between groups according to the included study author's power calculations. Coppin 2005 estimated a minimum sample size of 128 participants with complete outcomes, well above the 94 participants with complete outcomes included in this review.

\section{Limitations of the participants}

Coppin 2005 recruited participants aged 60 years and over who had been given a repeat prescription of quinine for night cramps in the previous three months. It is not known whether or not the quinine was effective. No inclusion criterion addressed the number of cramps affecting the participant in a defined period (for example, one week). It is possible that some of the included participants no longer experienced nighttime muscle cramp, perhaps due to the effect of the prescribed quinine tablets. Also, no inclusion criterion addressed the location of the nighttime cramp. While nighttime cramp often affects the calf muscle, other muscles of the lower limb and upper limb muscles can be affected. It is not known how many of the included participants experienced nighttime calf cramp. This limits the justifiability of offering a stretching program that targeted only the calf muscles.

\section{Limitations of the intervention}

The stretching intervention advice offered in Coppin 2005 is described in full in the table Characteristics of included studies. To summarise, participants were asked to stretch both calf muscles at the same time by leaning towards a wall for $10 \mathrm{~s}$, three times throughout the day.

As muscle stretching has never before been evaluated in a RCT for treating muscle cramp, no direct comparisons in the literature can be found. In a systematic review of stretching before or after exercising to reduce delayed onset muscle soreness, risk of injury, and athletic or sporting performance, calf muscle stretching consisted of two separate stretches of soleus and gastrocnemius muscles held for $20 \mathrm{~s}$ on each limb, with a total stretch time of $160 \mathrm{~s}$ (Herbert 2002).

The stretches prescribed in Coppin 2005 may be less intense (by stretching both limbs at the same time) and held for a shorter time than is ideal and than calf stretches routinely recommended in clinical practice.

As discussed above, this calf muscle stretching intervention was given to all participants, regardless of the location of their nighttime muscle cramp. This may not reflect standard clinical practice, where stretching therapies are targeted at the affected muscles.

\section{Limitations of the outcome measure}

From the description in the published paper, participants were asked in a postal survey 12 weeks from baseline to recall how many night cramps they had experienced in the previous four weeks. This outcome is subject to recall bias. The outcome also does not focus on the number of calf muscle cramps experienced. As the stretching interventions targeted only the calf muscles, the effect of calf muscle stretching on calf muscle cramp is an important, yet unaddressed, component of the outcome measure.

There are no data available on the severity of cramps experienced. This is an important outcome in trials of interventions for muscle cramps, as it is possible that the severity of cramp may reduce without a notable reduction in cramp frequency.

\section{Potential biases in the review process}

None

\section{Agreements and disagreements with other studies or reviews}

The effect of non-drug therapies for lower limb muscle cramp has never before been systematically reviewed.

\section{A U THORS' CONCLUSIONS}

\section{Implications for practice}

Evidence from RCTs is too limited in quantity and quality to provide clinical direction for the use of any type of non-drug therapy for any type of lower limb muscle cramps.

\section{Implications for research}

This review highlights the urgent need for rigorously designed RCTs to evaluate the effectiveness of non-drug therapies for lower limb muscle cramps. Future research should explore the effectiveness of a wide range of the available non-drug therapies for cramp 
associated with exercise, pregnancy, haemodialysis, sleep and neurological conditions. Published reports of future trials should include high quality descriptions of all aspects of methodology to enable appraisal and interpretation of results. Outcomes should at least include cramp severity and frequency, and measures of frequency should not rely on participants retrospectively recalling the number of cramps experienced over a period of time.

More research is required to determine clinical important difference values for people experiencing nighttime muscle cramp to improve power calculations in future research.

\section{ACKNOWLEDG E M N T S}

We thank Dr Richard Coppin and Professor Paul Little for providing raw data for use in this review and Francoise Schyns, Professor Deirdre Walsh and Professor Michel Vayssairat for responding to requests for additional information about their research to determine eligibility for inclusion.

The Cochrane Neuromuscular Disease Group editorial base is supported by the MRC Centre for Neuromuscular Disease, the Motor Neurone Disease Association and the Muscular Dystrophy Campaign.

\section{R E F E R E N C E S}

\section{References to studies included in this review}

Coppin 2005 \{published and unpublished data\} Coppin RJ, Wicke DM, Little PS. Managing nocturnal leg cramps--calf-stretching exercises and cessation of quinine treatment: a factorial randomised controlled trial. British Journal of General Practice 2005;55(512):186-91. [PUBMED: 15808033]

\section{References to studies excluded from this review}

Cappy 1999 \{published data only\}

Cappy C, Jablonka J, Schroeder E. The effects of exercise during hemodialysis on physical performance and nutrition assessment. Journal of Renal Nutrition 1999;9(2):63-70.

Carpenter 1995 \{published data only\}

Carpenter S, Tjaden B, Rock JA, Kimball A. The effect of regular exercise on women receiving danazol for treatment of endometriosis. International Journal of Gynacology and Obstetrics 1995;49(3):299-304.

Cramp 1995 \{published data only\}

Cramp M, Scott O. Long term electrical stimulation increases strength and fatigue resistance in the human adult quadriceps femoris. 12th International Congress World Confederation for Physical Therapy Washington D.C. 1995; Vol. 30:597.

Goodwin 2007 \{published data only\} Goodwin J, Glaister M, Howatson G, Lockey R, McInnes G. Effect of pre-performance lower-limb massage on thirtymeter sprint running. Journal of Strength \& Conditioning Research 2007;21(4):1028-31.

Ippolito 2008 \{published data only\}

Ippolito E, De Luca S, Sommaruga S, Grassellino V, Nappi G. Experimental-clinical study on the effects of hydromassage with Thermae Oasis's salsobromoiodine water in chronic venous stasis disease of the lower extremities. Minerva Cardioangiologica 2008;56(4):401-8.

Laessøe 2004 \{published data only\}

Laessøe L, Nielsen JB, Biering-Sørensen F, Sønksen J. Antispastic effect of penile vibration in men with spinal cord lesion. Archives of Physical Medicine \& Rehabilitation 2004;85(6):919-24.

Lawani 2003 \{published data only\}

Lawani M, Alihonou E, Akplogan B, Poumarat G, Okou L, Adjadi N. Effect of antenatal gymnastics on childbirth: a study on 50 sedentary women in the Republic of Benin during the second and third quarters of pregnancy [L'effet de la gymnastique prénatale sur l'accouchement : étude sur 50 femmes béninoises sédentaires au cours des deuxième et troisième trimestres de grossesse [French]]. Sante 2003;13 (4):235-241.

Liu 2009 \{published data only\}

Liu N, Mao L, Sun X, Liu L, Yao P, Chen B. The effect of health and nutrition education intervention on women's postpartum beliefs and practices: a randomized controlled trial. BMC Public Health 2009;9(45):10.1186/1471-24589-45.

Mauss 1970 \{published data only\}

Mauss, H. Muscular cramp in the calf caused by pregnancy. Therapy in a blind study [Schwangerschaftsbedingte Wadenkrampfe: Therapie im Blindversuch [German]]. Medizinische Welt 1970;36:1570-1571.

Miller 2007 \{published data only\} Miller L, Mattison P, Paul L, Wood L. The effects of transcutaneous electrical nerve stimulation (TENS) on spasticity in multiple sclerosis. Multiple Sclerosis 2007;13 (4):527-533.

Nilsson 2008 \{published data only\} Nilsson SE. Electromagnetic therapy in restless legs syndrome and nocturnal leg muscle cramps. Same effect of pulsating electromagnetic fields and placebo [Elektromagnetisk terapi vid restless legs och nattliga vadmuskelkramper. Pulserande elektromagnetiska fält och placebo gav samma effekt [Swedish]]. Lakartidningen 2008; 105(32-33):2167-70.

Schyns 2009 \{published data only\} Schyns F, Paul L, Finlay K, Ferguson C, Noble E. Vibration therapy in multiple sclerosis: a pilot study exploring its effects on tone, muscle force, sensation and functional performance. Clinical Rehabilitation 2009;23(9):771-81. 


\section{Stern 1966 \{published data only\}}

Stern FH. Leg cramps in geriatric diabetics with peripheral vascular ischemia: treatment. Journal of the American Geriatrics Society 1966;14(6):609-16.

Thaler 2001 \{published data only\}

Thaler E, Huch R, Huch A, Zimmerman R. Compression stockings prophylaxis of emergent varicose veins in pregnancy: a prospective randomised controlled study. Swiss Medical Weekly 2001;131(45-46):659-62.

\section{Vayssairat 2000 \{published data only\}}

Vayssairat M, Ziani E, Houot B. Placebo controlled efficacy of class 1 elastic stockings in chronic venous insufficiency of the lower limbs [Efficacité versus placebo de la contention classe 1 dans l'insuffisance veineuse chronique des membres inférieurs [French]]. Journal des Maladies Vasculaires 2000; 25(4):256-62.

Warke 2006 \{published data only\}

Warke K, Al-Smadi J, Baxter D, Walsh D, Lowe-Strong A. Efficacy of transcutaneous electrical nerve stimulation (TENS) for chronic low-back pain in a multiple sclerosis population: a randomized, placebo-controlled clinical trial. Clinical Journal of Pain 2006;22(9):812-9.

Wei 2006 \{published data only\}

Wei L, Wei-min H. Applicability of the preventative exercise for office workers. Journal of Clinical Rehabilitative Tissue Engineering Research 2008;12(24):4767-72.

Xue 2006 \{published data only\}

Xue J, Bai L, Guo Q, Yang C, Lu J. Efficacy of early intervention of motor relearning program on post-stroke hemiplemia: a randomized controlled observation. Neural Regeneration Research 2006;1(3):277-9.

\section{Additional references}

\section{Abdulla 1999}

Abdulla A, Jones P, Pearce V. Leg cramps in the elderly: prevalence, drug and disease associations. International Journal of Clinical Practice 1999;53(7):494-6.

\section{Angeli 1996}

Angeli P, Albino G, Carraro P, Dalla Pria M, Merkel C, Caregaro L, et al.Cirrhosis and muscle cramps: evidence of a causal relationship. Hepatology 1996;23(2):264-73.

\section{Baltodano 1988}

Baltodano N, Gallo BV, Weidler DJ. Verapamil vs quinine in recumbent nocturnal leg cramps in the elderly. Archives of Internal Medicine 1988;148(9):1969-70.

\section{Bentley 1996}

Bentley S. Exercise-induced muscle cramp. Proposed mechanisms and management. Sports Medicine 1996;21(6): 409-20.

Burnakis 2000

Burnakis GT. Gabapentin for leg cramps: muscling in on quinine. Hospital Pharmacy 2000;35(8):887-90.

\section{Burns 2009}

Burns J, Ryan MM, Ouvrier RA. Evolution of foot and ankle manifestations in children with CMT1A. Muscle \& Nerve 2009;39(2):158-66.

Butler 2002

Butler JV, Mulkerrin EC, O'Keeffe ST. Nocturnal leg cramps in older people. Postgraduate Medical Journal 2002; 78(924):596-8.

\section{Canzanello 1992}

Canzanello V, Burkart J. Hemodialysis-associated muscle cramps. Seminars in dialysis 1992;5:299-304.

\section{Connolly 1992}

Connolly P, Shirley E, Wasson J, Nierenberg D. Treatment of nocturnal leg cramps. A crossover trial of quinine vs vitamin E. Archives of Internal Medicine 1992;152(9): 1877-81.

\section{Cutler 1984}

Cutler P. Cramps in the legs and feet. Journal of the American Medical Association 1984;252(1):98.

\section{Daniell 1979}

Daniell HW. Simple cure for nocturnal leg cramps. New England Journal of Medicine 1979;301(4):216.

\section{Dunn 1993}

Dunn NR. Effectiveness of quinine for night cramps. British Journal of General Practice 1993;43(368):127-8.

\section{El-Tawil 2010}

El-Tawil S, Al Musa T, Valli H, Lunn MPT, El-Tawil T, Weber M. Quinine for muscle cramps. Cochrane Database of Systematic Reviews 2010, Issue 12. [DOI: 10.1002/ 14651858.CD005044]

Forshew 2003

Forshew DA, Bromberg MB. A survey of clinicians' practice in the symptomatic treatment of ALS. Amyotrophic Lateral Sclerosis and Other Motor Neuron Disorders 2003;4(4): 258-63.

Fowler 1973

Fowler AW. Relief of cramp. Lancet 1973;1(7794):99.

Frusso 1999

Frusso R, Zárate M, Augustovski F, Rubinstein A. Magnesium for the treatment of nocturnal leg cramps: a crossover randomized trial. Journal of Family Practice 1999; 48(11):868-71.

\section{Garrison 2011}

Garrison SR, Allan GM, Sekhon RK, Musini VM, Khan KM. Magnesium for skeletal muscle cramps. Cochrane Database of Systematic Reviews 2011, Issue 11. [DOI: 10.1002/14651858.CD009402]

\section{Gentili 1997}

Gentili A, Weiner DK, Kuchibhatil M, Edinger JD. Factors that disturb sleep in nursing home residents. Aging 1997;9 (3):207-13

\section{Gootnick 1943}

Gootnick A. Night cramps and quinine. Archives of Internal Medicine 1943;71(4):555-62. 


\section{Gulich 1998}

Gulich M, Heil P, Zeitler H-P. Epidemiology and determinants of nocturnal calf cramps. European Journal of General Practice 1998;4(3):109-13.

\section{Haskell 1997}

Haskell SG, Fiebach NH. Clinical epidemiology of nocturnal leg cramps in male veterans. American Journal of the Medical Sciences 1997;313(4):210-4.

\section{Herbert 2002}

Herbert R, Gabriel M. Effects of stretching before and after exercising on muscle soreness and risk of injury: systematic review. British Medical Journal 2002;325(7362):468.

Higgins 2011

Higgins JPT, Green S (editors). Cochrane Handbook for Systematic Reviews of Interventions Version 5.1.0 [updated March 2011]. The Cochrane Collaboration, 2011 Available from www.cochrane-handbook.org.

Hirai 2000

Hirai M. Prevalence and characteristics of muscle cramps in patients with varicose veins. VASA 2000;29(4):269-73.

\section{Jansen 1991}

Jansen PH, Joosten EM, Van Dijck J, Verbeek AL, Durian FW. The incidence of muscle cramp. Journal of Neurology, Neurosurgery and Psychiatry 1991;54(12):1124-5.

\section{Jansen 1991a}

Jansen PH, van Dijck JA, Verbeek AL, Durian FW, Joosten E M. Estimation of the frequency of the muscular pain-fasciculation syndrome and the muscular crampfasciculation syndrome in the adult population. European Archives of Psychiatry and Clinical Neuroscience 1991;241(2): $102-4$.

\section{Jansen 1997}

Jansen PH, Veenhuizen KC, Wesseling AI, de Boo T, Verbeek AL. Randomised controlled trial of hydroquinine in muscle cramps. Lancet 1997;349(9051):528-32.

\section{Jansen 1999}

Jansen PH, Lecluse RG, Verbeek AL. Past and current understanding of the pathophysiology of muscle cramps: why treatment of varicose veins does not relieve leg cramps. Journal of the European Academy of Dermatology and Venereology 1999;12(3):222-9.

\section{Jansen 2002}

Jansen PH, Gabreëls FJ, van Engelen BG. Diagnosis and differential diagnosis of muscle cramps: a clinical approach. Journal of Clinical Neuromuscular Disease 2002;4(2):89-94.

\section{Joekes 1982}

Joekes AM. Cramp: a review. Journal of the Royal Society of Medicine 1982;75(7):546-9.

\section{Jones 1983}

Jones K, Castleden CM. A double-blind comparison of quinine sulphate and placebo in muscle cramps. Age and Ageing 1983;12(2):155-8.

\section{Kanaan 2001}

Kanaan N, Sawaya R. Nocturnal leg cramps. Clinically mysterious and painful-but manageable. Geriatrics 2001;56 (6):34,39-42.

\section{Kobrin 2007}

Kobrin SM, Berns JS. Quinine - a tonic too bitter for hemodialysis-associated muscle cramps?. Seminars in Dialysis 2007;20(5):396-401.

\section{Leclerc 1996}

Leclerc KM, Landry FJ. Benign nocturnal leg cramps. Current controversies over use of quinine. Postgraduate Medicine 1996;99(2):177-8, 181-4.

\section{Leung 1999}

Leung AK, Wong BE, Chan PY, Cho HY. Nocturnal leg cramps in children: incidence and clinical characteristics. Journal of the National Medical Association 1999;91(6): 329-32.

\section{Manjra 1996}

Manjra S, Schwellnus M, Noakes T. Risk factors for exercise associated muscle cramping (EAMC) in marathon runners. Medicine and Science in Sports and Exercise 1996;28(5 Supplement):S167.

\section{Matsumoto 2009}

Matsumoto M, Watanabe K, Tsuji T, Ishii K, Takaishi $\mathrm{H}$, Nakamura M, et al.Nocturnal leg cramps: a common complaint in patients with lumbar spinal canal stenosis. Spine 2009;34(5):E189-94.

Miller 2005 Miller TM, Layzer RB, Miller M, Layzer Robert B. Muscle cramps. Muscle and Nerve 2005;32(4):431-42.

\section{Moss 1948}

Moss HK, Herrmann LG. Night cramps in human extremities: a clinical study of the physiologic action of quinine and prostigmine upon the spontaneous contraction of resting muscles. American Heart Journal 1948;35(3): 403-8.

\section{Naylor 1994}

Naylor JR, Young JB. A general population survey of rest cramps. Age and Ageing 1994;23(5):418-20.

\section{Norris 1957}

Norris FH Jr, Gasteiger EL, Chatfield PO. An electromyographic study of induced and spontaneous muscle cramps. Electroencephalography and Clinical Neurophysiology 1957;9(1):139-47.

\section{Oboler 1991}

Oboler SK, Prochazka AV, Meyer TJ. Leg symptoms in outpatient veterans.. Western Journal of Medicine 1991;155 (3):256-9.

\section{Redmond 2009}

Redmond AC, Burns J, Ouvrier RA. Factors that influence health-related quality of life in Australian adults with Charcot-Marie-Tooth disease. Neuromuscular Disorders 2009;18(8):619-25. 
RevMan 2011

Copenhagen: The Nordic Cochrane Centre, The Cochrane Collaboration. Review Manager (RevMan) [Computer program]. Version 5.1.. Copenhagen: The Nordic Cochrane Centre, The Cochrane Collaboration, 2011.

Riley 1995

Riley JD, Antony SJ. Leg cramps: differential diagnosis and management. American Family Physician 1995;52(6): $1794-8$.

\section{Roberts 1965}

Roberts H. Spontaneous leg cramps and 'restless legs' due to diabetogenic hyperinsulinism: observations on 131 patients. Journal of the American Geriatrics Society 1965;13 (7):602-38.

Roffe 2002

Roffe C, Sills S, Crome P, Jones P. Randomised, crossover, placebo controlled trial of magnesium citrate in the treatment of chronic persistent leg cramps. Medical Science Monitor 2002;8(5):CR326-30.

\section{Schwellnus 2007}

Schwellnus MP. Muscle cramping in the marathon: aetiology and risk factors. Sports Medicine 2007;37(4-5): 364-7.

\section{Shaker 2005}

Shaker HK, Mackler L, Huber TE. What is the diagnostic approach to a patient with leg cramps?. Journal of Family Practice 2005;54(9):817-8.

\section{Simchak 1991}

Simchak AC, Pascuzzi RM. Muscle cramps. Seminars in Neurology 1991;11(3):281-7.

\section{Sohrabvand 2006}

Sohrabvand F, Shariat M, Haghollahi F. Vitamin B supplementation for leg cramps during pregnancy. International Journal of Gynacology and Obstetrics 2006;95 (1):48-9.

\section{Sontag 1988}

Sontag SJ, Wanner JN. The cause of leg cramps and knee pains: an hypothesis and effective treatment. Medical Hypotheses 1988;25(1):35-41.

\section{Sulzer 2005}

Sulzer NU, Schwellnus MP, Noakes TD. Serum electrolytes in ironman triathletes with exercise-associated muscle cramping. Medicine and Science in Sports and Exercise 2005; 37(7):1081-5.

\section{Warburton 1987}

Warburton A, Royston JP, O'Neill CJ, Nicholson PW, Jee $\mathrm{RD}$, Denham MJ, et al.A quinine a day keeps the leg cramps away?. British Journal of Clinical Pharmacology 1987;23(4): 459-65.

\section{Weber 2003}

Weber M, Feinberg D. Treatment for cramps in amyotrophic lateral sclerosis/motor neuron disease (Protocol). Cochrane Database of Systematic Reviews 2003, Issue 2. [DOI: 10.1002/14651858.CD004157]

\section{Young 1993}

Young JB, Connolly MJ. Naftidrofuryl treatment for rest cramp. Postgraduate Medical Journal 1993;69(814):624-6.

\section{Young 2002}

Young G, Jewell D. Interventions for leg cramps in pregnancy. Cochrane Database of Systematic Reviews 2002, Issue 4. [DOI: 10.1002/14651858.CD000121]

Young 2009

Young G. Leg cramps. Clinical Evidence 2009;03(1113): $1-10$.

\section{Yunus 1996}

Yunus MB. Restless leg syndrome and leg cramps in fibromyalgia syndrome: a controlled study. British Medical Journal 1996;312(7042):1339.

* Indicates the major publication for the study 


\title{
CHARACTERISTICS OF STUDIES
}

\author{
Characteristics of included studies [ordered by study ID]
}

\author{
Coppin 2005
}

Methods Factorial design randomised control trial for the first 6 weeks. After 6 weeks, participants were told that they could continue the exercises if they wished and also decide themselves whether or not to continue or resume taking quinine tablets. Participants were also given an instruction sheet describing the exercise programme and confirming the advice Data collection took place between January 1999 and September 2001

Participants

Participants were recruited through 28 general practices in southern England. Database searching at each practice identified potential participants, who were then contacted by letter

Inclusion criteria: people aged 60 years and over who had been given a repeat prescription by their general practitioner of quinine for nocturnal (night) cramps in the previous 3 months. Cramp was not defined in the published report

Exclusion criteria: People with conditions significantly limiting their ability to undertake the stretching exercises (for example, severe osteoarthritis); leg pain that might be confused with cramp (for example, severe peripheral vascular disease); inability to reliably report on symptoms (for example, dementia); and patients who described being previously taught leg exercises aimed at preventing cramp

Interventions

Participants were given advice to either continue or discontinue taking quinine tablets (this review includes data only from participants who were allocated to continue quinine use) and to undertake a daily programme of either stretching or placebo exercises for which they received training

The placebo exercise was devised to be of comparable duration and simplicity to the intervention stretching exercise, but was passive and involved negligible stretching of the muscles of the calf and foot. An attempt was made to minimise intervention contamination by terming the stretching and placebo exercises as 'standing' and 'lying' exercises, respectively

Patients were then shown how to complete a 6-week diary record

One week later the nurse telephoned the patient to check that they were coping with the diary recording. Intervention advice was not repeated

For the stretching exercise the nurse gave participants the following instruction, "First remove your shoes, then stand facing a wall 2 to 3 feet away so that the tips of your fingers are just touching the wall. Lean forward keeping your heels in contact with the floor, keep your body straight and use your arms to control your forward tilt until you feel a moderately intense, but not painful, 'pulling sensation' in your calf muscles. This stretching position should be held for 10 seconds (count 1 elephant, 2 elephants, etc.). Stand upright and relax for 5 seconds, then repeat the stretch for a further 10 seconds. Carry out this sequence three times spread through each day"

For the non-stretching exercise the nurse advised participants as follows, "First lie face up on your bed or on the floor so that your legs are out straight. Gently bend your knees up and move them towards your chest keeping your feet flat on the bed or floor. When your feet are as near your bottom as you can get them without causing discomfort, hold that position for 10 seconds (count 1 elephant, 2 elephants, etc.). Straighten your legs out and relax for 5 seconds then repeat the exercise for a further 10 seconds. Carry out 
this sequence three times spread through each day"

Baseline: The baseline questionnaire recorded cramp symptoms according to frequency
over the previous 4 weeks and severity on a 4-point descriptive scale. Overall symptom
burden was assessed using the mean of 3 7-point Likert scale scores assessing "disrupted
activity“, "sleep quality“, and "overall problems with cramp in the past week“. Each
Likert scale used the same format as the MYMOP (Measure Yourself Medical Outcome
Profile). Quinine usage over the previous 4 weeks was also recorded

A 6-week diary was used by participants to record daily cramp symptoms, intervention compliance, and weekly symptom burden scores

12 weeks from baseline, participants were sent a self-completion postal questionnaire. Non-responders were telephoned to record their questionnaire responses

The 12-week self-completion postal questionnaire recorded cramp symptoms, quinine usage and frequency of taught exercises over the previous week

Notes

NHS Executive SE Project Grant SPGS787/SW

Risk of bias

\begin{tabular}{|c|c|c|}
\hline Bias & Authors' judgement & Support for judgement \\
\hline
\end{tabular}

Random sequence generation (selection Low risk

"Randomised by the research assistant usbias) ing random number tables"

Allocation concealment (selection bias) Low risk

Blinding of participants and personnel Low risk (performance bias)

All outcomes
"Randomisation to the trial took place when the nurse opened a sealed, numbered, opaque envelope containing intervention instructions"

"The placebo exercise was devised to be of comparable duration and simplicity to the intervention stretching exercise, but was passive and involved negligible stretching of the muscles of the calf and foot. We sought to minimise intervention contamination by terming the stretching and placebo exercises as "standing" and "lying' exercises, respectively",

Indicator of successful blinding: "By 12 weeks people performed the exercises 3 to 4 times per week, and although the nonstretch group did them slightly more frequently, this was not significant (placebo = 3.79 times per week, stretch $=3.07$ times per week, $\mathrm{t}=1.71, \mathrm{P}=0.09$ )" 


\section{Coppin 2005 (Continued)}

Blinding of outcome assessment (detection Low risk bias)

All outcomes

Incomplete outcome data (attrition bias) Unclear risk All outcomes

Selective reporting (reporting bias) High risk

Other bias

High risk 12-week data included in this review: participant-completed postal questionnaire

12 weeks: $0 / 49$ missing from intervention group, $1 / 48$ missing data; $0 / 48$ missing from control group, 2/48 missing data. Reasons for missing data not explained

The online protocol (ISRCTN26051665) states that outcomes would include duration of leg cramps and subsequent GP attendance. Outcome data are not provided in the published paper

Participants were allowed to discontinue or swap treatments after 6 weeks. Results of outcomes measures for each group after 12 weeks might not reflect the effect of the intervention allocated at baseline

After 12 weeks, participants were asked to recall how many night cramps they had experienced in the preceding 4 weeks. Participants might be subject to recall bias

Characteristics of excluded studies [ordered by study ID]

\begin{tabular}{ll}
\hline Study & Reason for exclusion \\
\hline Cappy 1999 & Not a RCT \\
\hline Carpenter 1995 & $\begin{array}{l}\text { Lower limb muscle cramp was not an isolated measured outcome (reported the percentage of participants who } \\
\text { reported muscle cramps; not specific to the lower limbs). Authors did not respond to requests for more information }\end{array}$ \\
\hline Cramp 1995 & Lower limb muscle cramp was not a measured outcome \\
\hline Goodwin 2007 & $\begin{array}{l}\text { Lower limb muscle cramp was not a measured outcome. } \\
\text { Intervention given for less than 4 weeks }\end{array}$ \\
\hline Ippolito 2008 & $\begin{array}{l}\text { Intervention given for less than 4 weeks. } \\
\text { Unclear if a RCT. } \\
\text { Lower limb muscle cramp was not an isolated measured outcome (symptom clump: pain, heaviness, paraesthesia, } \\
\text { nocturnal cramps, restless leg syndrome and pruritus. As a group, rated from 0 (never present) to } 3 \text { (always present) } \\
\text { ) }\end{array}$
\end{tabular}


(Continued)

Laessøe 2004 Lower limb muscle cramp was not a measured outcome (spasm in people with spinal cord lesion) Intervention given for less than 4 weeks

Lawani 2003 Lower limb muscle cramp was not a measured outcome

Liu 2009 Lower limb muscle cramp was not an isolated measured outcome (symptom clump: leg pain or joint pain) Did not assess non-drug therapy (dietary advice)

Mauss 1970 Did not assess non-drug therapy (horse chestnut seed extract versus placebo)

Miller $2007 \quad$ Lower limb muscle cramp was not a measured outcome (spasticity in people with multiple sclerosis) Intervention given for less than 4 weeks

Nilsson 2008 Unable to isolate participants with nocturnal leg cramps from participants with restless leg syndrome. Authors did not respond to requests for more information

Lower limb muscle cramp pain was not a measured outcome. A 10-point visual analogue scale was used as a measure of quality of life, from 0 (absence of symptoms) to 10 (worst symptoms). It was considered that $0=$ poor quality of life due to discomfort; $10=$ condition did not diminish the quality of life. This scale is not validated

Schyns 2009 Lower limb muscle cramp was not a measured outcome (spasm and spasticity in people with multiple sclerosis). Confirmed by study author Francoise Schyns

Stern 1966 Did not assess non-drug therapy (papaverine hydrochloride)

Thaler 2001 Lower limb muscle cramp was not an isolated measured outcome (symptom clump: leg pain, discomfort or cramps; rated as a group as unchanged, better or worse)

Vayssairat 2000 Lower limb muscle cramp was not an isolated measured outcome (symptom clump: lower limb pain, cramps and heaviness; rated as a group). Confirmed with author Michel Vayssairat

Warke 2006 Lower limb muscle cramp was not a measured outcome (spasm in people with multiple sclerosis). Confirmed by study author Deirdre Walsh

Wei $2006 \quad$ Lower limb muscle cramp was not a measured outcome.

Not a RCT

Xue $2006 \quad$ Lower limb muscle cramp was not a measured outcome. 
DATA ANDANALYSES

Comparison 1. Calf muscle stretching versus placebo stretching for lower limb muscle cramps

\begin{tabular}{|c|c|c|c|c|}
\hline Outcome or subgroup title & $\begin{array}{l}\text { No. of } \\
\text { studies }\end{array}$ & $\begin{array}{c}\text { No. of } \\
\text { participants }\end{array}$ & Statistical method & Effect size \\
\hline $\begin{array}{l}1 \text { Number of cramps in the last } \\
\text { four weeks }\end{array}$ & 1 & & Mean Difference (IV, Fixed, 95\% CI) & Subtotals only \\
\hline
\end{tabular}

\section{H I S T O R Y}

Protocol first published: Issue 4, 2010

Review first published: Issue 1, 2012

\section{CONTRIBUTIONSOFAUTHORS}

FB was responsible for selecting trials; contacting authors of studies; assessing risk of bias; extracting, entering and analysing data; interpreting results; and writing the review. KW was responsible for selecting trials; assessing risk of bias; checking data extraction and entry; and providing comments on the draft review. JB and VC were responsible for providing comments on the draft review. All authors agreed on the final text.

\section{DECLARATIONSOF INTEREST}

FB received a research grant from The University of Newcastle, Australia, to support completion this review. The University of Newcastle did not interfere with the independence of the authors in regard to the conduct of the review and did not delay or prevent publication of this review.

VC: none known

KW: none known

JB receives research funding from the National Health and Medical Research Council of Australia, NIH Rare Diseases Inherited Neuropathies Consortium, Charcot-Marie-Tooth Disease Association of Australia, Australian Podiatry Education \& Research Foundation.

\section{SOURCES OF SUPPORT}




\section{Internal sources}

- Fiona Blyton, Vivienne Chuter, Kate Walter, Australia.

The University of Newcastle, Faculty of Health

- Fiona Blyton, Joshua Burns, Australia.

The University of Sydney, Sydney Medical School

- Joshua Burns, Australia.

Institute for Neuromuscular Research, The Children's Hospital at Westmead

\section{External sources}

- No sources of support supplied

\section{DIFFERENCES BETWEEN PROTOCOLANDREVIEW}

'Risk of bias' assessment was updated to suit revision of the Cochrane Handbook for Systematic Reviews of Interventions guidelines.

A 'Summary of Findings' table was included to suit revision of the Cochrane Handbook for Systematic Reviews of Interventions guidelines.

We clarified the 'Types of participants' description in the Methods. The published protocol stated 'All people (including men, women and children) who experience lower limb muscle cramp will be included.' We added the following sentence to clarify: "We included cramp during any activity or condition, including (but not limited to) cramp associated with exercise, pregnancy, haemodialysis, sleep and neurological conditions". This change did not alter our inclusion criteria.

\section{NDEX TERMS}

\section{Medical Subject Headings (MeSH)}

*Lower Extremity; Muscle Cramp [*therapy]; Muscle Relaxants, Central [therapeutic use]; Muscle Stretching Exercises [*methods]; Quinine [therapeutic use]; Randomized Controlled Trials as Topic

\section{MeSH check words}

Aged; Humans; Middle Aged 